\title{
SIMPLIFIED METHODOLOGY TO EVALUATE THE EXTERNAL SULFATE ATTACK IN CONCRETE STRUCTURES
}

\author{
Tai Ikumi ${ }^{a}$, Sergio H. P. Cavalaro ${ }^{a}$, , Ignacio Segura $^{a}$, Albert de la Fuente ${ }^{a}$ and Antonio \\ Aguado $^{\mathrm{a}}$ \\ ${ }^{a}$ Department of Construction Engineering, Universitat Politècnica de Catalunya Barcelona Tech, Jordi \\ Girona 1-3, C1, E-08034 Barcelona, Spain \\ * Corresponding author: Sergio H. P. Cavalaro. Department of Construction Engineering, Universitat \\ Politècnica de Catalunya Barcelona Tech, Jordi Girona 1-3, C1, E-08034 Barcelona, Spain. Email \\ address: sergio.pialarissi@upc.edu, Tel: +34 934016507 Fax: +34 934011036
}

\begin{abstract}
The external sulfate attack is a degradation process that causes expansion and cracking in concrete structures. Due to the absence of simplified methodologies to predict the potential damage, codes specify that sulfate resistant cement should be used whenever the surrounding sulfate concentration surpasses a predefined limit. This may lead to penalizing measures as the size of the element or the mechanical properties of the concrete used are not considered. In the present work, an alternative approach is proposed. A simplified chemo-mechanical methodology is deducted to assess the potential damage in concrete elements exposed to sulfate rich environments. Equations to estimate the penetration of sulfates are derived from a numerical model taking into account sulfate consumption, acceleration of the penetration induced by cracking and decrease in diffusivity caused by pore filling. Failure modes associated to this phenomenon are analyzed and a set of equations to assess the risk of failure are deducted. Finally, a parametric study with different geometries of elements and surrounding sulfate contents is performed. The results show that the criterion included in codes might be modified depending on the characteristics of the structure.
\end{abstract}

Keywords: Concrete; Durability; External sulfate attack; Diffusion; Failure

\section{1.- INTRODUCTION}

The external sulfate attack (ESA) is a complex phenomenon in which chemical reactions, ionic transport and mechanical damage interact with each other, leading to expansions and degradation in concrete structures [1-4]. The degradation progresses as sulfate ions from the outside penetrate the element and react with compounds from the hydrated cement paste. As a result, a multi-layered pattern is formed with an external damaged layer and an internal sound core [5]. The mechanical interactions between these zones play a major role in determining the damage induced by the attack.

The ESA has special relevance in underground or foundation structures in contact with sulfate-rich soils. Such structures remain covered during most of their service life, which compromises the early diagnostic of the attack that may only be detected after severe material degradation has occurred. The existing tools to account for potential 
damage caused by ESA in real structures may be gathered in three main groups: procedures included in building codes, empirical models and integrated models.

Building codes have traditionally specified precautionary measures to protect concrete against this type of attack. The most common approach is based on the definition of exposure classes regulated by the sulfate content in the media surrounding the structure. Depending on the classification obtained, prescriptions of maximum water/cement ratio, minimum compressive strength and type of cement should be followed to avoid durability problems (e.g. Model Code 2010, BS 8500-1:2006, ACI 201.2R-08, UNE EN 206-1:2008). Notice that the size of the element under study or the mechanical properties of the concrete used are not considered. In fact, through the application of this criterion, practitioners are not able to predict the potential damage of the attack or the compliance of a minimum service life. This may lead to penalizing measures and cost overruns as a result of unnecessary use of sulfate resistant cement in some cases.

Several empirical models have been developed to quantify the spalling depth or the evolution of expansions of concrete elements exposed to ESA. Most of them are based on experience or accelerated laboratory tests performed with small specimens (e.g. [68]). The main drawbacks associated with these models are their limited applicability since they are only valid for elements subjected to the same conditions used in the tests. Integrated models take into account the transport of ions, the chemical reaction and the microstructural damage through several differential equations, whose solution commonly require iterative procedures. At present, these models provide the most precise assessment of the ESA. However, the complexity of the equations involved and the high computational cost for their solution may not be accessible to practitioners and certainly are not compatible with the philosophy of most design codes. Besides, the majority of the integrated models from the literature are only capable of predicting the expansion and the damage at a micro-scale level. To estimate the macro-structural response in terms of cracking and failure, advanced structural models should be used, thus compromising even more the straightforward assessment of the attack.

It is evident that a simplified methodology for the assessment of the potential damage caused by the ESA compatible with the philosophy of building codes is still needed. The objective of this paper is to propose this simplified methodology considering both the micro and macro scale effects. First, the latest integrated models from the literature are analyzed. Based on this, the model by Ikumi et al. [9] is selected and used to derive straightforward equations for the reactive-transport phenomenon accounting for the sulfate consumption, the acceleration of the penetration due to micro-cracking and the decrease in diffusivity due to pore filling. Then, a comprehensive study of the common mechanical failure modes associated with the ESA is presented and a set of simplified equations to assess the failure of the structure are derived. A parametric study is conducted to evaluate the methodology proposed for different geometries under a wide range of realistic field conditions. Based on this study, reference values are proposed for the aluminate content depending on the type and the dimensions of the structure. 
103

104

The methodology developed here represents a step forward on how to assess the ESA explicitly in the design of concrete structures. It allows a more detailed evaluation of the durability of the structures since the specific conditions and expected service life are considered. As a result, an optimized definition of precautionary measures may be obtained for each application.

\section{2.- INTEGRATED MODELS}

Table 1 summarizes some of the integrated models developed during the last decade. This table does not include models that consider ettringite formation through a solidstate mechanism since it is believed that it must occur through solution [10].

Table 1. Integrated models developed during the last decade

\begin{tabular}{cccc}
\hline Authors & Year & Expansion mechanism & Expansive products \\
\hline Tixier and Mobasher [11,12] & 2003 & Volume increase & Ettringite \\
\hline Bary et al. [13] & 2008 & Crystallization pressure & Ettringite and gypsum \\
\hline Sarkar et al. [14] & 2010 & Volume increase & Ettringite \\
\hline Idiart et al. [15] & 2011 & Volume increase & Ettringite \\
\hline Zuo et al. [16] & 2012 & Volume increase & Ettringite \\
\hline Cefis and Comi [17] & 2014 & Volume increase & Ettringite \\
\hline Bary et al. [18] & 2014 & $\begin{array}{c}\text { Crystallization } \\
\text { pressure/Volume increase }\end{array}$ & Ettringite \\
\hline Ikumi et al. [9] & 2014 & Volume increase & Ettringite \\
\hline Nie et al. [19] & 2015 & Volume increase & Ettringite
\end{tabular}

Controversy still exists on basic topics of the ESA, especially regarding the expansion mechanism and the gypsum role on the expansion process [3,20]. Amongst the several mechanisms suggested to explain how the precipitation of ettringite leads to expansion, mainly two theories have been implemented in comprehensive models: the volume increase and the crystallization theories.

According with the first of them, expansions are a result of the additional volume generated by ettringite formation [11,21]. In this case, the response of the matrix and the expansive stresses are calculated from the imposed volumetric strains. According with the second of them, expansions are caused by the crystallization pressure exerted on the pore walls due to the formation of a supersaturated solution within small pores [22,23]. In this case, the actual driving pressure that will be translated into strains is obtained by different modifications of the Correns equation [24,25]. Even though the latter theory is supported by recent publications [10,26,27], it requires a very complex chemical approach once the evolution of phases in the pore solution has to be monitored during the attack in terms of chemical activities. Moreover, it was shown by [13] that, despite predicting the cracking state with a relatively good accuracy, this theory leads to macroscopic expansions about two orders of magnitude smaller than the found in experimental data. According to Zhang et al. [28], the reason is that the crystallization pressure assessment is based in an elastic approach that does not account for 
microcraking and differed deformations (creep), which may play an important role in the final strain measured.

In a recent publication [18], Bary et al. tried to solve this issue by introducing an additional macroscopic bulk strain due to the increase of volume produced by secondary ettringite formation. The authors used the equation derived by Tixier and Mobasher [11] and subsequently used by many other researchers $[9,14,15]$. By adding this consideration, the expansions are a result of both the additional volume generated by ettringite formation and the crystallization pressure exerted on the pore walls by the supersaturated solution. Free expansions calculated with this approach is similar to the obtained in the test of specimens. Bary et al. also pointed out that the contribution of the crystallization pressure is negligibly small compared to the bulk strain produced by secondary ettringite formation [18], which would indicate that the volume increase is the overriding factor in the macroscopic strain evolution.

Like Bary et al., other studies from the literature [9] also suggest that the volume increase and the crystallization theories may be compatible as they probably represent two different stages of the sulfate attack. When the solubility limit of ettringite is reached due to the ingress of sulfate ions, the system always tend to return to an equilibrium state through ettringite precipitation. When this energy cannot be released by crystal precipitation, it is released in the form of pressure to the pore walls and the subsequent microcracking as described in the crystallization pressure theory. Microcraking decreases the pressure conditions in the pore, thus allowing ettringite to precipitate near the cracks. Therefore, macroscopic free strains increase proportionally to the amount of ettringite precipitated, being the volume increase inherent to this chemical reaction the driving force of the macroscopic strains. In other words, the initiation of the macroscopic strains arises mainly from the action of the crystallization pressure, while the macroscopic free expansions are explained by the volume increase.

Considering that the aim of the present study is to generate simplified models capable of estimating the expansive strain and the failure at a macro-structural level, an integrated model based on the volume increase was selected. This also contributes to a more straightforward approach since a smaller number and simpler input parameters are required to estimate the expansions in the volume increase theory. Therefore, the integrated model by Ikumi et al. [9] was selected as the basis to develop the simplified methodology since it also introduces a more direct and intuitive consideration for the damage assessment and thereby facilitate the definition of the input parameters.

It is important to remark that this model only provides the expansion and the damage at a small-scale level. To evaluate the overall response at a macro-scale level and the failure of the structure, Ikumi et al. [9] and other authors suggest that the expansions estimated should be implemented in finite element models that account for the mechanical response of the structure. This represents an important limitation found in 
practically all integrated models from the literature, which are unable to provide a straightforward verification of the durability of the structure in terms of global failure.

\section{3.- SIMPLIFIED METHODOLOGY}

The methodology proposed in this paper is based on the application of a set of simplified equations to assess the extent of the reactive-transport process and the possible mechanical structural failure at a given service life. As outlined in Figure 1, the aggressiveness of the media and the reactivity of the material define the input parameters for the simplified reactive-transport equations that provide the maximum sulfate penetration and the maximum expansion in the damaged layer of the element. This information combined with the geometric and mechanical characteristics of the element allows the verification of the most common mechanical failure modes. If no mechanical failure occurs and the serviceability is not compromised, it is considered that the structure will comply with the required service life.

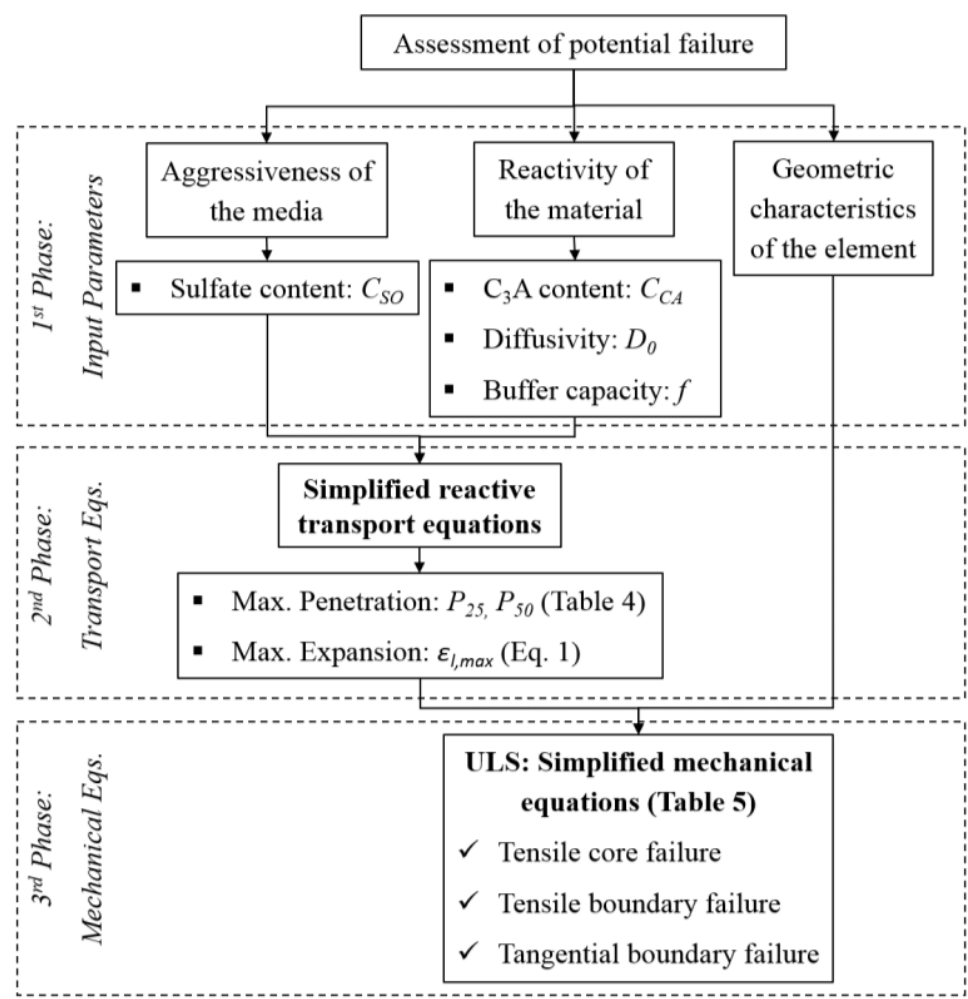

Fig. 1. Outline of the simplified methodology for the durability assessment of the ESA

\section{1- SIMPLIFIED REACTIVE-TRANSPORT EQUATIONS}

In this section, simplified equations to quantify the maximum penetration of the sulfate front and the maximum linear micro-strains at 25 and 50 years are deduced. As these equations are derived from the model described by Ikumi et al. [9], firstly the main features of the model and the hypothesis adopted here are presented. 3.1.1 Hypothesis adopted based on the integrated model by Ikumi et al. [9] 
It is assumed that expansions are caused by the volume increase associated to secondary ettringite formation, being the expansive nature of gypsum disregarded. To simplify the model, all hydrated aluminates are considered in the form of monosulfate $\left(C_{4} A \bar{S} H_{12}\right)$ since this should be the predominant aluminate phase in hydrated Portland cement pastes at long ages.

Sulfate and aluminate concentrations are computed through a diffusion-reaction model based on the Fick's second law, which takes into account the ingress of sulfate ions under a concentration gradient and its depletion due to ettringite formation. The effective diffusivity $(D)$ is affected by pore filling, which reduces the paths for additional sulfate diffusion, and micro-cracking and spalling of the cementitious matrix. The latter increases the diffusivity as more paths towards the inner layers may be found.

The upper bound of the diffusivity reached when the material is completely damaged is set to $10^{-10} \mathrm{~m}^{2} / \mathrm{s}$. This value is slightly below the diffusivity of sulfates in free solution, which Gerard and Marchand [29] quantified as $10^{-9} \mathrm{~m}^{2} / \mathrm{s}$ for ions able to move freely within cracks. For the simulations performed in this paper, the value of $c_{1}$ and $c_{2}$ described in [9] were defined respectively as 3 and 6.93, in accordance with the recommendation from [30]. The characteristic cracking length $\left(l_{c h}\right)$ is fixed at $26 \mathrm{~mm}$, following the validation by [9].

Expansions at micro scale are calculated by the additional volume generated by the reaction product $(\Delta V / V)$ [21]. This calculation gives a $55 \%$ volume increase when monosulfate is converted into ettringite. The total linear strain $\left(\varepsilon_{1}\right)$ associated with this expansion is computed by multiplying the expansion factor by the amount of monosulfate reacted $\left(C_{C_{4} A \bar{S} H_{12}}^{r e a c t}\right)$, as described in Eq. 1 . The term $M / \rho$ corresponds to the molar volume of monosulfate and $C_{C_{4} A \bar{S} H_{12}}^{\text {react }}$ is expressed as a molar concentration. Notice that the maximum expansive strain $\left(\varepsilon_{\text {l.max }}\right)$ may be calculated with Eq. 1 by assuming that all monosulfate react to form ettringite.

$$
\varepsilon_{1}=\left(1+\frac{\Delta V}{V} \frac{M}{\rho} C_{C_{4} A \bar{S} H_{12}}^{r e a c t}-f \varphi_{0}\right)^{1 / 3}-1
$$

Since ettringite precipitates within the pore network, the matrix is able to accommodate a certain amount of expansive product without exerting any pressure to the pore walls $[11,14,31]$. Consequently, not all aluminate present will generate expansions. The expression presented by Tixier \& Mobasher [11] is used to estimate the buffered expansion. This is represented in the second term of Eq. 1, in which $\varphi_{0}$ is the initial porosity of the matrix and $f$ is the fraction of this porosity that may be filled by expansive products before expansions occur. According with Tixier \& Mobasher [11], $f$ usually ranges between 0.05 and 0.40 . 
In the majority of underground structures subjected to the ESA, the diffusion flux may be classified as approximately linear - typical in diaphragm walls or tunnels - or radialtypical in piled foundations. Transport processes in radial direction are subjected to flux intensification as sulfate penetrates towards the center of the element, concentrating at a smaller area. Conversely, no intensification occurs in a linear flux.

In a simplified methodology, it is convenient to minimize the number of equations proposed. Therefore, prior to deriving the simplified equations, the sulfate penetration in radial elements is compared with that from linear elements. The aim is to demonstrate that both provide similar results for most real size structures, thus justifying the use of the linear flux formulation for the majority of cases.

The maximum penetration depths obtained through linear and radial flux approximation were compared for radius ranging from 5 to $50 \mathrm{~cm}$. A minimum sulfate content of $1 \%$ of the sulfate concentration in the external surface is defined as a threshold to calculate the penetration depth. Table 2 presents the parameters used in the analysis defined according with the literature. The material used corresponds to a concrete with 350 $\mathrm{kg} / \mathrm{m}^{3}$ of cement that contains $80 \%$ clinker and $10.8 \%$ of $\mathrm{C}_{3} \mathrm{~A}$. Total time simulated is fixed at 25 years. Space intervals of $0.25 \mathrm{~mm}$ and variable time steps were considered to ensure stability and convergence.

Table 2. Parameters used in the preliminary study of the flux intensification effect

\begin{tabular}{ccccccc}
\hline $\begin{array}{c}\boldsymbol{k} \\
{\left[\mathbf{m}^{3} / \mathbf{m o l} \cdot \mathbf{s}\right]}\end{array}$ & $\begin{array}{c}\boldsymbol{D}_{\mathbf{0}} \\
{\left[\mathbf{m}^{2} / \mathbf{s}\right]}\end{array}$ & $\begin{array}{c}\boldsymbol{C}_{\boldsymbol{S O}} \\
{\left[\mathbf{m o l} / \mathbf{m}^{3} \text { water }\right]} \\
([\mathrm{g} / \mathbf{l}])\end{array}$ & $\begin{array}{c}\boldsymbol{C}_{\boldsymbol{C A}} \\
{\left[\mathbf{m o l} / \mathbf{m}^{3} \text { concrete }\right]} \\
\left(\left[\mathbf{\%} \mathbf{C}_{3} \mathbf{A}\right]\right)\end{array}$ & $\begin{array}{c}\boldsymbol{f}_{\boldsymbol{c m}} \\
{[\mathbf{M P a}]}\end{array}$ & $\boldsymbol{f}$ & $\boldsymbol{\varphi}_{\boldsymbol{o}}$ \\
\hline 0 or $10^{-8}$ & $10^{-12}$ & $\begin{array}{c}34.37 \\
(3.3)\end{array}$ & $\begin{array}{c}112 \\
(10.8)\end{array}$ & 30 & 0.05 & 0.1 \\
\hline
\end{tabular}

Figure 2 shows the penetrations depths obtained in the analysis. When no chemical reaction is considered $(k=0)$, the radial and the linear flux provide approximately the same penetration depth for radius of more than $20 \mathrm{~cm}$. The flux intensification observed in radial fluxes reduces the entrance of sulfates and decreases slightly the penetration. This is reasonable since the rate of transfer of a substance in accordance with Fick's second law is proportional to the concentration gradient measured along the diffusion direction. Once the differences in concentrations are smaller in radial fluxes due to the intensification effect, smaller penetration depths should be expected.

When sulfate depletion caused by the chemical reaction is considered $\left(k=10^{-8}\right.$ $\mathrm{m}^{3} / \mathrm{mol} \cdot \mathrm{s}$ ), the penetration depth is reduced approximately by a factor of 8 in both models. This indicates that chemical reactions are the governing process in the initial stages of the transport phenomenon. In this case, the linear flux and the radial flux approaches provide virtually the same results. 


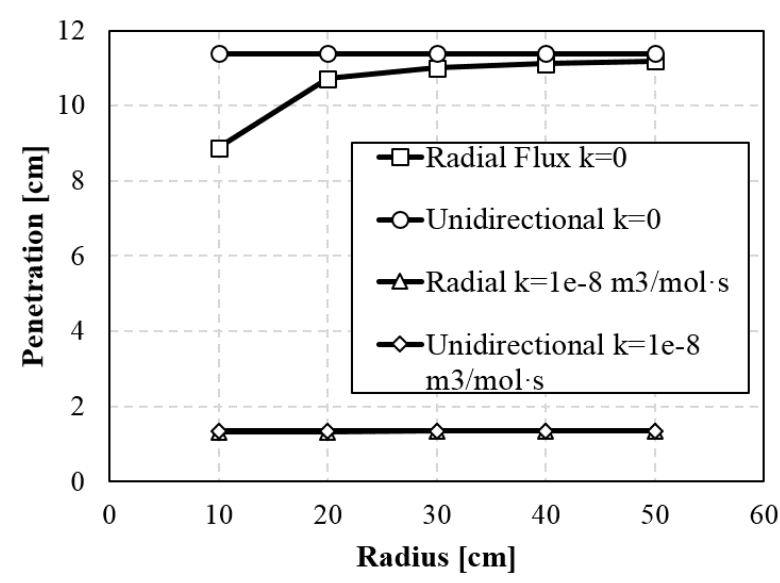

Fig. 2. Flux intensification effect

The analysis performed confirms the small differences between both approaches simulated, especially when the chemical reactions are considered. Moreover, the linear flux approximation provides a prediction of the penetration depth on the safe side given that slightly higher values are obtained. Therefore, in this work a linear flux is adopted for all structural typologies, thus avoiding the definition of two different formulations and the consideration of the element size in the simplified reactive-transport equations.

\subsection{3- Definition of input parameters}

To derive the simplified transport equations, penetration depths obtained through the model by [9] are fitted to a straightforward numerical formulation. Since several parameters are needed in the model by [9], the first step to obtain simplified equations is to detect which of the parameters are the most relevant. For that, a sensibility analysis is conducted with the values defined in Table 3, which are based on recommendations from the literature and found in practice. The range defined for the aluminate content $\left(C_{C A}\right)$ correspond to a concrete with $350 \mathrm{~kg} / \mathrm{m}^{3}$ of cement that contain $80 \%$ of clinker and from $4 \%$ to $12 \%$ of $\mathrm{C}_{3} \mathrm{~A}$. The reference value is equivalent to cement with $8 \%$ of $\mathrm{C}_{3} \mathrm{~A}$.

Table 3. Ranges of parameters and penetration front variation in sensibility analysis

\begin{tabular}{cccc:c}
\hline Parameter & Minimum & Reference & Maximum & $\begin{array}{c}\text { Penetration depth } \\
\text { variation [cm] }\end{array}$ \\
\hline$C_{S O}\left[\mathrm{~mol} / \mathrm{m}^{3}\right.$ water $]([\mathrm{g} / \mathrm{l}])$ & $6.25(0.6)$ & $34.37(3.3)$ & $62.5(6.0)$ & 1.4 \\
$D_{0}\left[\mathrm{~m}^{2} / \mathrm{s}\right]$ & $10^{-12}$ & $5 \cdot 10^{-12}$ & $10^{-11}$ & 1.4 \\
$f[-]$ & 0.0 & 0.1 & 0.4 & 0.8 \\
$C_{C A}\left[\mathrm{~mol} / \mathrm{m}^{3}{ }_{\text {concrete }}\right]\left(\left[\% \mathrm{C}_{3} \mathrm{~A}\right]\right)$ & $41(4)$ & $83(8)$ & $124(12)$ & 0.8 \\
$\varphi_{o}$ & 0.08 & 0.10 & 0.14 & 0.3 \\
$f_{c m}[\mathrm{MPa}]$ & 20 & 30 & 40 & 0.1 \\
\hline
\end{tabular}

In practice, the kinetics of the reactions $(k)$ and the temperature might affect the penetration of sulfates. However, nowadays no widely accepted test to quantify this parameter is available. Therefore, it does not seem reasonable to leave the selection of $k$ to the final user. For that reason, $k$ is not considered as a variable in this study. Instead, 
a constant $k$ of $10-8 \mathrm{~m} 3 / \mathrm{mol} \cdot \mathrm{s}$ was selected for all analyses given that other authors traditionally assume values that range from $10-10$ to $10-6 \mathrm{~m} 3 / \mathrm{mol} \cdot \mathrm{s}$ [32].

In the sensibility analysis, a linear flux was simulated considering the same time steps and mesh size of section 3.1.2. Simulations were performed by varying parameters one by one between the maximum and the minimum values, whereas the other parameters were kept equal to the reference values. This procedure is repeated for all parameters from Table 3. In each case, the difference between the penetration depths estimated with the maximum and the minimum values is calculated and presented in Table 3 .

The sulfate content and the initial diffusion coefficient are the most influencing parameters. Conversely, the compressive strength and initial porosity show a smaller influence over the penetration depth. Based on these results, $C_{S O}, D_{0}, f$ and $C_{C A}$ are considered explicitly as input variables of the simplified reactive-transport equations. On the other hand, $f_{c m}$ and $\varphi_{o}$ are assumed constant and equal to their reference values for the estimation of the equations that govern the reactive-transport phenomenon (notice that $f_{c m}$ is a variable in the equations developed in later sections to assess the risk of failure).

\subsection{4- Proposal of equations}

A new study with the model by Ikumi et al. [9] was conducted to derive the simplified reactive-transport equations. At this time, simulations were performed with multiple combinations of the most influencing parameters with several values within the ranges listed in Table 3. More than 2000 simulations were completed at 25 and 50 years. Once a sufficiently big database of penetration depths was obtained, a nonlinear numerical regression was applied to derive the simplified equations that yield the best fit with the numerical results. The final formulations obtained to estimate the penetration depth at 25 and 50 years $\left(P_{25}\right.$ and $\left.P_{50}\right)$ are presented in Table 4.

Table 4. Simplified reactive-transport equations

\begin{tabular}{|c|c|c|}
\hline $\begin{array}{c}\text { Service Life } \\
\text { [years] }\end{array}$ & $\begin{array}{c}\text { Simplified reactive transport formulation } \\
{[\mathrm{cm}]}\end{array}$ & $\begin{array}{c}K_{95} \\
{[\mathrm{~cm}]}\end{array}$ \\
\hline 25 & $P_{25}=\left(7 e 10 D_{0}+0.035 C_{S O}\right) \exp \left(\frac{6.65 e 11 D_{0}+10.737}{C_{C A}}-\frac{1 e-10}{35 D_{o}} f\right)$ & 0.65 \\
\hline 50 & $P_{50}=1.26 P_{25}$ & 0.86 \\
\hline
\end{tabular}

The initial diffusivity $\left(D_{0}\right)$ is introduced in $\mathrm{m}^{2} / \mathrm{s}$, whereas the aluminate content $\left(C_{C A}\right)$ is expressed in mol per cubic meter of concrete. The sulfate content $\left(C_{S O}\right)$ is expressed in mol of sulfate per cubic meter of water. As these equations are deduced from the model described by Ikumi et al. [9], sulfate consumption, acceleration of the penetration due to cracking and decrease of diffusivity due to pore filling are indirectly considered. Figure 3.a and 3.b depict the correlation between the penetration depths obtained through the integrated model by [9] and with Eq. 2 or Eq. 3. Correlation coefficients of 0.91 and 

the input parameters remain within the ranges defined in Table 3.

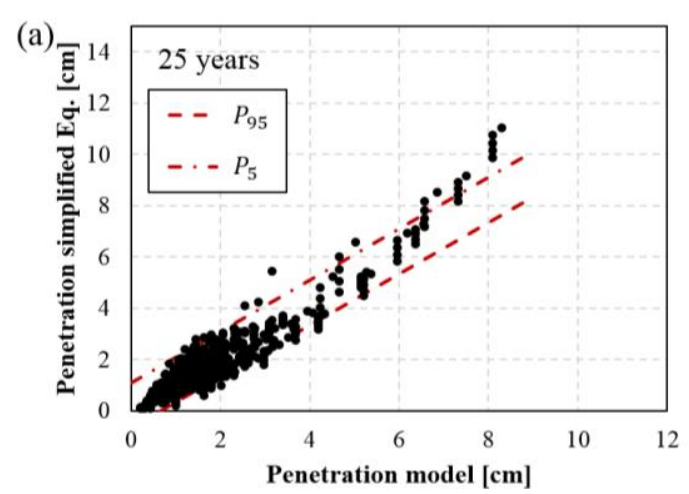

(c)

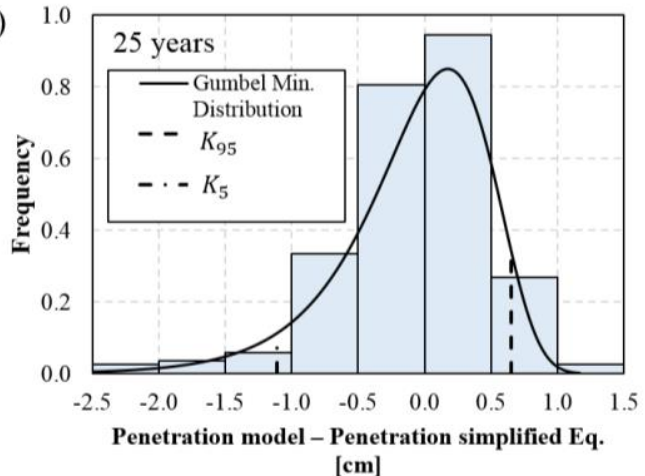

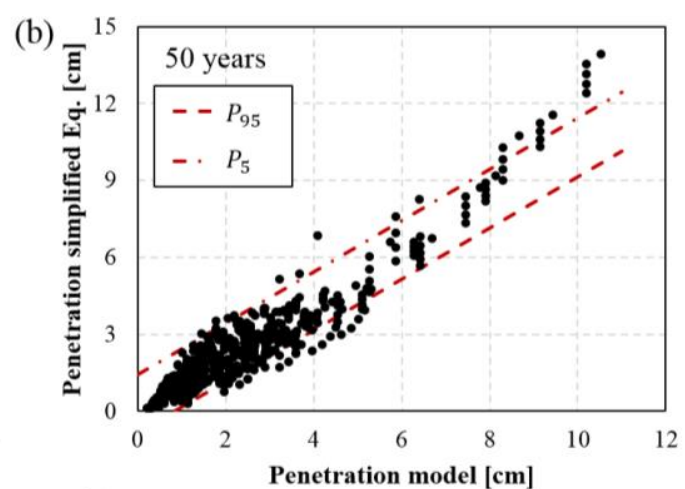

(d)

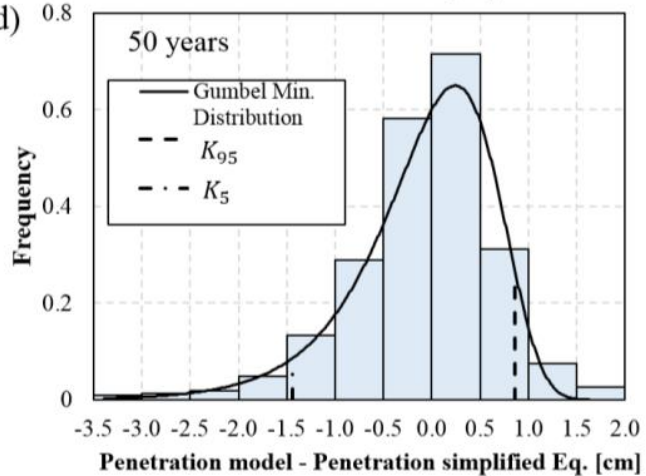

Fig. 3. Correlation between penetration obtained with integrated model and simplified equation ( $a$ and $b$ ); Gumbel distribution to assess error of estimation ( $c$ and $d$ )

Even though the simplified reactive-transport equations provide a fair approximation of the integrated model, in some situations it might be necessary to use estimations on the safe side. Therefore, a statistical analysis was performed in order to assess the error of prediction of Eq. 2 and Eq. 3. As shown in Figures 3.c and 3.d, the frequency of the error of estimation was fit to a Gumbel distribution (minimum extreme value type I). Then, the distribution was used to assess the minimum penetration depth that had to be summed to the obtained with the simplified equations in order to assure a $95 \%$ of probability of achieving values above the calculated with the integrated model by [9]. This additional value $\left(K_{95}\right)$ is shown in Table 4 and should be directly added to Eq. 2 and Eq. 3 in case a safer estimation is required.

For the chemical reaction rate $(k)$ considered in the literature, it has been demonstrated that the aluminates of the exterior layers are rapidly consumed by the ingressing sulfates [9]. This means that the maximum expansive strain $\left(\varepsilon_{\text {l.max }}\right)$ is rapidly reached at the surface layers of the element. Once the aluminates are consumed, the sulfates advance at a higher rate to the inner layers, reacting with new aluminates present. Hence, an abrupt variation of the expansion should occur close to the penetration front.

Figure 4 shows in continuous lines the typical strain profiles due to ESA in structures under symmetric (sulfate insource from all sides) or asymmetric sulfate exposure 
conditions (sulfate insource from only one side). To simplify the structural consideration of the ESA, the strain profile depicted with the red discontinuous line is used instead. It assumes that $\varepsilon_{\text {l.max }}$ estimated with Eq. 1 occurs along the whole penetration depth obtained with Eq. 2 or Eq. 3, which is a hypothesis on the safe side.
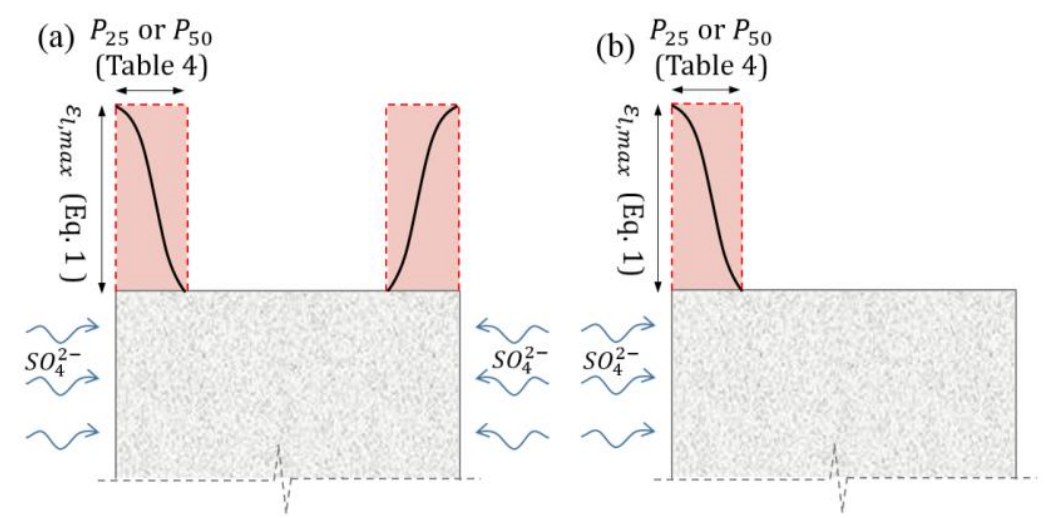

Fig. 4. Strain profiles for symmetric (a) and asymmetric (b) sulfate exposure

\section{2- SIMPLIFIED MECHANICAL EQUATIONS}

Although expansion due to ettringite formation is concentrated in the surficial layers, strains also appear in the sound core of the element to maintain compatibility. In fact, the sound core acts as a restriction that reduces the expansion calculated with Eq. 1. An auto-balanced tension state is generated, leading to possible mechanical failures outside the zone directly affected by the sulfate penetration and by the attack. Three failures modes are distinguished: tensile failure of the sound core, tangential failure and tensile failure in the boundary between the surficial layers and the sound core.

Micro-cracks in the external layers of the element due to high compressive stresses are usually developed prior to any failure mode. Generally, the micro-cracking is localized, affecting only a few millimeters closer to the surface. Therefore, it is not considered a failure mode as it does not imply the macro-structural failure of the element. The superficial micro-cracking modifies the local mechanical properties and the sulfate diffusion coefficient. This phenomenon is taken into account in the simplified methodology by a degradation of the elastic modulus and an increase in the diffusion coefficient in the zone directly affected by the sulfate penetration. Notice that interactions with other elements in contact with the structure directly under attack (such as external loads or strain constraints in specific directions) could modify the stresses profile and affect the failure. However, these considerations cannot be included in a simplified methodology as they will vary depending on each study case.

\subsection{1- Tensile failure of the sound core}

The expansions of the outer layers along the length of the element are restrained due to the stiffness provided by the sound inner core. This causes normal compressive stresses 
$\left(\sigma_{c}\right)$ at the surficial layers, while normal tensile stresses $\left(\sigma_{t c}\right)$ appear at the sound inner core. If $\sigma_{t c}$ reaches the tensile strength of concrete, the inner core might crack, reducing significantly the restrains applied to the external layers. This might produce a release of the restricted strains and an abrupt displacement of the structure. In Figure 5, such situation is represented before and after cracking for elements under symmetric and asymmetric sulfate exposure conditions.
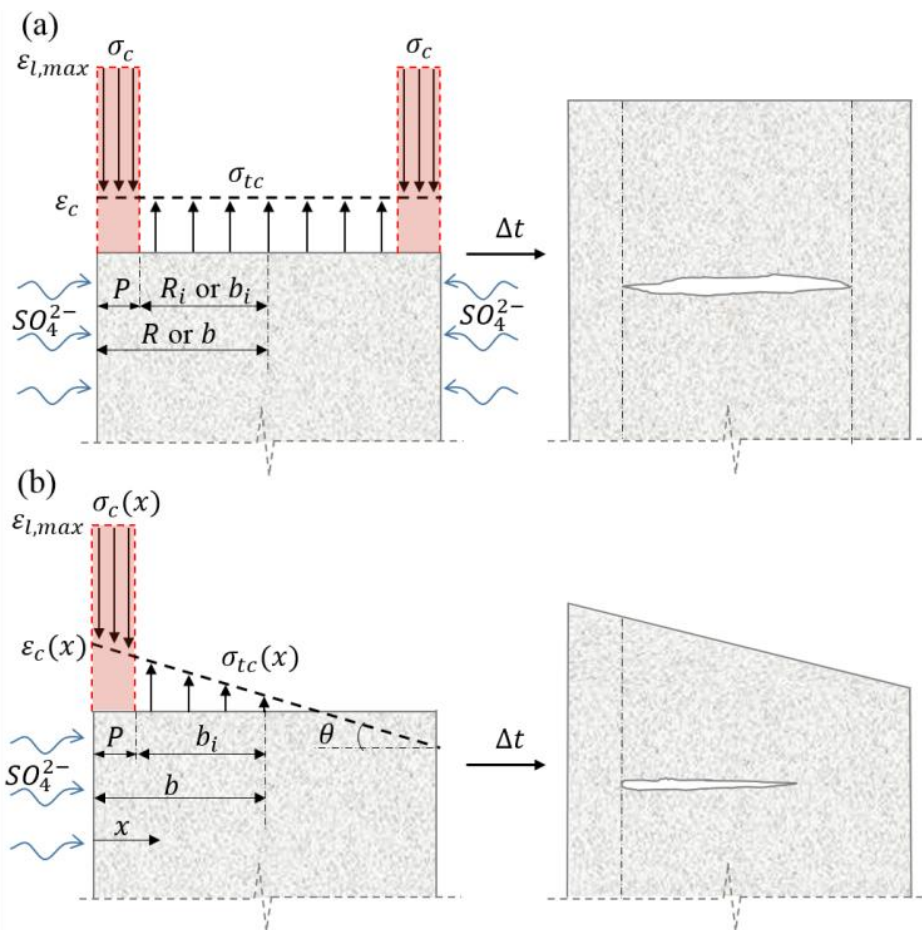

Fig. 5. Normal stress distribution in symmetric (a) and 1 face (b) sulfate exposure.

As an approximation, it is assumed that the Navier-Bernouilli hypothesis applies to the cross-section of the element. This means that the original cross-section (before any expansion occurs) should remain plane after the expansions take place. Consequently, the final strain $\left(\varepsilon_{c}\right)$ of the cross-section should follow the profile depicted as a discontinuous line in Figure 5. By imposing equilibrium in a simple sectional analysis (Eq. 4 to 6), it is possible to assess $\sigma_{c}$ and $\sigma_{t c}$.

$$
\begin{gathered}
N=0=\int_{\text {Area }} E(x) \cdot\left(\varepsilon_{c}(x)-\varepsilon_{l}(x)\right) \text { dArea } \\
M=0=\int_{\text {Area }} E(x) \cdot\left(\varepsilon_{c}(x)-\varepsilon_{l}(x)\right) x \partial \text { Area } \\
\varepsilon_{c}(x)=\varepsilon_{c}(x=0)+\zeta x
\end{gathered}
$$

The term $\zeta(<<1)$ represents the curvature of the cross-section. The stress level is calculated with Eq. 7 by multiplying the elastic modulus of the material $(E)$ and the difference between the total strain $\left(\varepsilon_{c}\right)$ and the non-mechanical strain $\left(\varepsilon_{l}\right)$. 


$$
\sigma(x)=E(x) \cdot\left[\varepsilon_{c}(x)-\varepsilon_{l}(x)\right]
$$

425

426

427

428

429

430

431

432

433

434

435

436

437

438

439

440

441

442

443

444

445

446

447

448

449

450

451

452

453

The value of $E$ is affected by the damage induced by the ESA, varying along the crosssection. In this sense, the sound core presents an elastic modulus $E_{0}$ that should be higher than the elastic modulus $E_{e}$ of the external layer affected by microcracking. To account for this effect on the structural formulation, $E_{e}$ is assumed constant along the external layer, whereas $E_{0}$ is set constant in the sound core. Even though no consensus exists in the literature on the quantification of the degradation of mechanical properties, most studies suggest that the strength loss for specimens may range between 10-50\% $[33,34]$.

Creep deformations were not considered in the simplified methodology proposed here as this implies an iterative calculation that would compromise the straightforwardness of the approach. Notice that creep deformations would reduce the internal stress level of the structural element, allowing the accommodation of part of the expansions.

Therefore, disregarding creep effects is a simplification on the safe side since it would lead to the calculation of higher stresses than the expected in reality. However, this assumption also affects the assessment of the displacements and the verification of the serviceability limit state since smaller strain levels than the expected in reality would be obtained with the formulation proposed here. If high precision is required in the assessment of the displacement, differed strains should be taken into account.

By solving Eq. 4 to 6 for different structural typologies and sulfate exposures, Eq. 8 to 10 are obtained to predict the maximum tensile stresses acting at a certain time in the cross-section (see Table 5). In the case of piles, $\mathrm{R}$ represents the total radius of the cross-section and $R_{i}$ is the radius of the sound core given by the difference between $R$ and the penetration depth $\mathrm{P}$ calculated with Eq. 2 or 3 . In the case of diaphragm walls or tunnels, $b$ represent the half thickness of the element.

Table 5. Simplified equations to predict the maximum stresses due to ESA

\begin{tabular}{|c|c|c|c|c|}
\hline $\begin{array}{c}\text { Struct. } \\
\text { typology }\end{array}$ & $\begin{array}{c}\text { Sulfate } \\
\text { exposure }\end{array}$ & $\begin{array}{c}\text { Tensile failure of the } \\
\text { sound core }\end{array}$ & Tangential boundary failure & $\begin{array}{c}\text { Tensile } \\
\text { boundary failure }\end{array}$ \\
\hline $\begin{array}{c}\text { Piles } \\
\text { (linear } \\
\text { elements) }\end{array}$ & Full & $\sigma_{t c}=\frac{E_{0} E_{e} \varepsilon_{l}\left(R^{2}-R_{i}^{2}\right)}{E_{e}\left(R^{2}-R_{i}^{2}\right)+E_{0} R_{i}^{2}}(8)$ & $\tau_{b}=\frac{E_{0} E_{e} \varepsilon_{l}\left(R^{2}-R_{i}^{2}\right) R_{i} \beta_{r}}{2\left(E_{e}\left(R^{2}-R_{i}^{2}\right)+E_{0} R_{i}^{2}\right)} \tanh \left(\frac{\beta_{r} l}{2}\right)$ & $\sigma_{t b}=\frac{\varepsilon_{l} E_{e} P}{R_{i}}$ \\
\hline $\begin{array}{l}\text { Diaphragm } \\
\text { walls or }\end{array}$ & 2 faces & $\sigma_{t c}=\frac{E_{0} E_{e} \varepsilon_{l} P}{E_{e} P+E_{0}(\mathrm{~b}-\mathrm{P})}$ & \multirow{2}{*}{$\tau_{b}=\frac{E_{0} E_{e} \varepsilon_{l} P b_{i} \beta}{E_{e} P+E_{0}(\mathrm{~b}-\mathrm{P})} \tanh \left(\frac{\beta l}{2}\right)$} & \multirow{2}{*}{-} \\
\hline $\begin{array}{c}\text { (surface } \\
\text { elements) }\end{array}$ & 1 face & $\sigma_{t c}=\frac{E_{0} \varepsilon_{l} P\left(3 P^{2}-9 P b+8 b^{2}\right)}{4 b^{3}}(10)$ & & \\
\hline
\end{tabular}

All equations included in Table 5 are able to assess mechanical failures at any time, as long as the penetration of sulfates are provided. The different mechanical failure modes considered and the corresponding stresses are treated separately in this paper. Even though a certain interaction might occur, it was assumed that one of the failure modes 
would happen because of the predominant stress. In case a more accurate prediction of the structural failure is needed, stresses from different mechanisms should be treated in a coupled way and more advanced simulations should be performed, for instance with coupled FEM.

\subsection{2- Tangential boundary failure}

Experimental studies show that mortar prisms exposed to ESA tend to present a layered spalling of the surface $[5,15]$. One of the possible mechanisms responsible for this phenomenon is depicted in Figure 6.

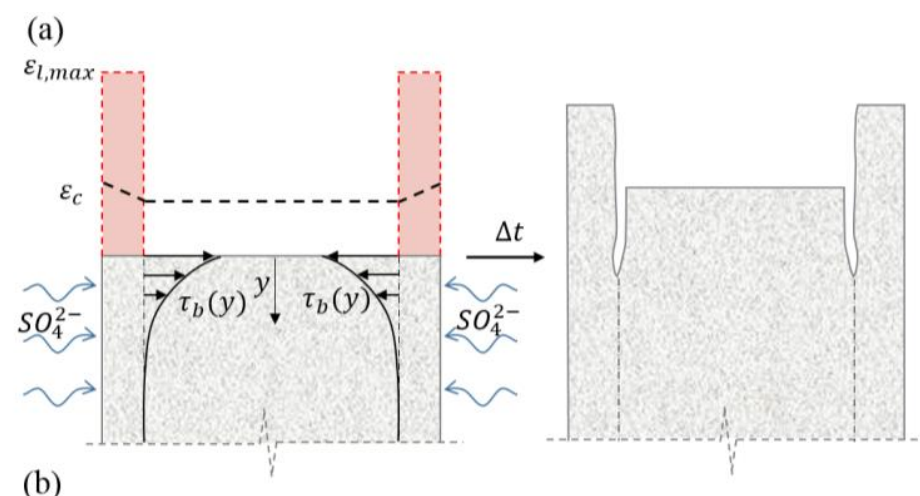

(b)

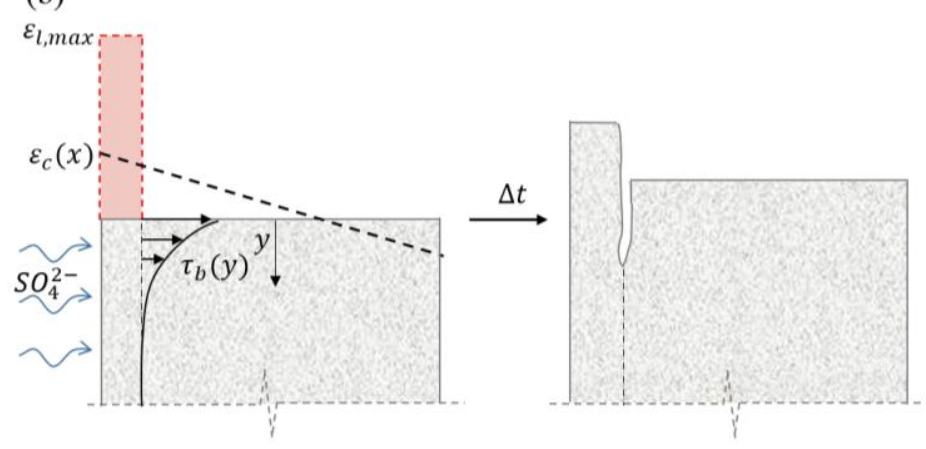

Fig. 6. Tangential stress distribution in symmetric (a) and 1 face (b) sulfate exposure.

Even though at intermediate sections the normal stresses distribution described in section 3.2.1 guarantees the compatibility of the deformation, at the top free crosssection of the element the compatibility has to be achieved through alternative mechanisms since no normal stresses exist. The difference in terms of vertical displacement creates tangential stresses between the surface layers affected by the ESA and the sound core. These should guarantee the compatibility of displacements at the extremities of the element. If the tangential stresses reach the tangential strength of the material, cracks might appear leading to the failure of the structure.

In this study, an analogy with the classical Mixing Theory for short fibers is applied [35-37] in order to deduct the equations to assess the tangential stresses. By imposing equilibrium and compatibility, Eq. 11 is obtained to estimate the tangential stresses $\left(\tau_{b}\right)$ between the sound core and the surface layers at the position $y$ along the axis of a pile. In this equation, $l$ is the length of the element, $\beta_{r}$ is a coefficient given by Eq. 12 and $G$ 
501

is the elastic shear modulus of concrete, which may be estimated from the elastic modulus. The maximum tangential stresses are located at the extremities of the element so that $y$ should be substituted by 0 in Eq. 11. This gives Eq. 13 (see Table 5) for the assessment of the maximum tangential stresses in piles.

$$
\begin{gathered}
\tau_{b}(y)=\frac{E_{0} \varepsilon_{c} R_{i} \beta_{r}}{2} \frac{\sinh \left[\beta\left(\frac{l}{2}-y\right)\right]}{\cosh \left(\beta \frac{l}{2}\right)} \\
\beta_{r}=\sqrt{\frac{2 G}{E_{0} R_{i}^{2} \ln \left(\frac{R}{R_{i}}\right)}}
\end{gathered}
$$

Analogous deductions may be performed for diaphragm walls or tunnels. Eq. 14 is obtained for such elements exposed to sulfates at 2 faces (see Table 5). The parameter $\beta$ should be calculated according with Eq. 15. The same formulation is also adopted when elements are exposed to the sulfate ingress only in one face. The curvature introduced by the asymmetric load increases the macroscopic strain in the external damaged layer and reduces the compressive stresses in this region. Therefore, the tangential stresses transmitted to the sound core are reduced, leading to an assessment on the safe side.

$$
\beta=\sqrt{\frac{G}{E_{0}(b-P) P}}
$$

It is important to remark $l$ only affects the assessment of the tangential stresses if the length of the element is below a critical value (around $1 \mathrm{~m}$ for most structures). For bigger values of $l$, the maximum tangential stress at the extremities of the element will remain approximately constant. Therefore, the parameter $l$ would not affect the stresses calculated in most structures.

\subsection{3- Tensile boundary failure}

In linear structures exposed all around to sulfates, the layered spalling may also be caused by a tensile boundary failure. As shown in Figure 7, tensile stresses $\left(\sigma_{t b}\right)$ are induced by the restrictions of the sound core to the expansions experienced by the affected layer in the cross-sectional plane. Cracks appear if the stresses reach the tensile strength of concrete.

Since the penetration depth tend to be significantly smaller than the radius of the element, an analogy with the thin-walled cylinders subjected to internal pressure may be made. The affected external layer would tend to present an expansion $\varepsilon_{l, \max }$ due to the ESA. This would generate stresses in the interface with the inner core, which would deform by $\varepsilon_{c e}$ along the diameter of the element. The restriction generates compressive stresses at the external surface affected by the ESA equal to $E_{e}\left(\varepsilon_{l, \text { max }}-\varepsilon_{c e}\right)$. 
(a)

(b) Top view
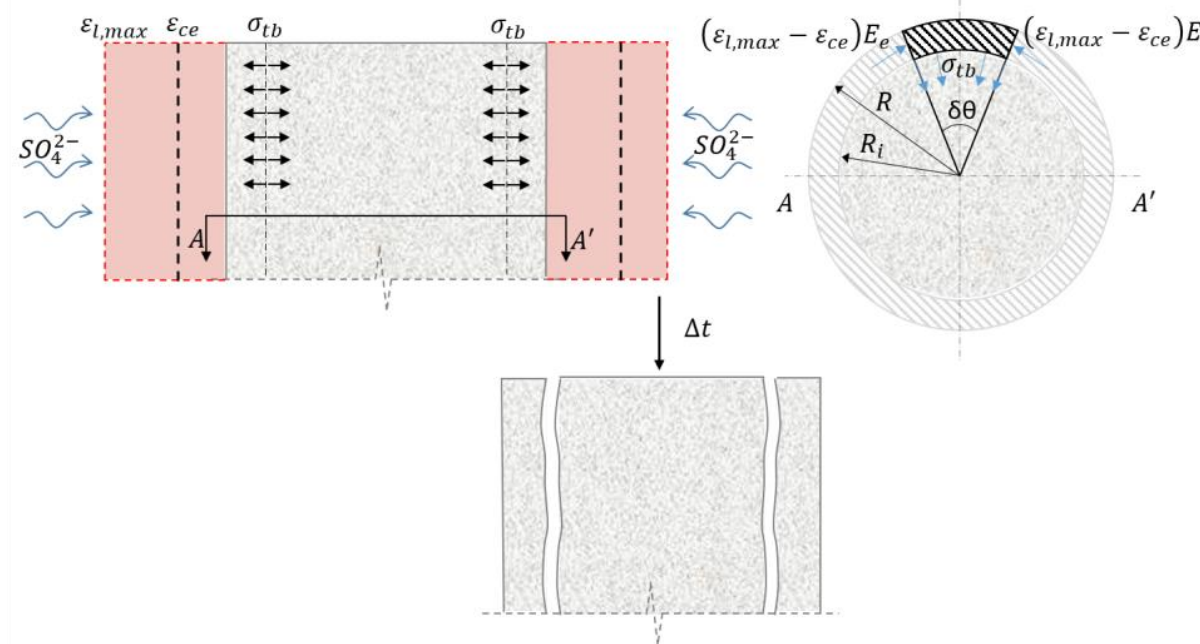

Fig. 7. Side view (a) and top view (b) of tensile stresses due to restrain of expansions in the crosssectional plane

These compressive stresses should be balanced by the tensile stresses $\sigma_{t b}$ acting in the interface with the sound core, as shown in Figure 7.b. By imposing equilibrium of the in-plane forces, Eq. 16 is obtained. Maximum tensile stresses occur when the external surface of the element is totally restrained by the sound core, that is, $\varepsilon_{c e}$ equals 0 . This gives Eq. 17, which should be used for the assessment of $\sigma_{t b}$ (see Table 5).

$$
\sigma_{t b}=\frac{P E_{e}\left(\varepsilon_{l . m a x}-\varepsilon_{c e}\right)}{R_{i}}
$$

\section{4.- PARAMETRIC STUDY}

A parametric study is performed to evaluate the results provided by the simplified methodology under a wide range of realistic conditions found in practice. Different sulfate concentrations in the media, aluminate contents and size of elements were evaluated. The results obtained are compared to those calculated with the integrated model by [9] and to the criteria from structural codes.

Table 6 shows the ranges and the reference values assumed for the two parameters considered in the study. All sulfate concentrations $\left(C_{S O}\right)$ evaluated correspond to moderately or highly aggressive exposure classes according to UNE EN 206-1. The range defined for the aluminate content $\left(C_{C A}\right)$ correspond to a concrete with $350 \mathrm{~kg} / \mathrm{m}^{3}$ of cement that contain $80 \%$ of clinker and from $4 \%$ to $12 \%$ of $\mathrm{C}_{3} \mathrm{~A}$. The reference value is equivalent to cement with $10 \%$ of $\mathrm{C}_{3} \mathrm{~A}$. Initial diffusivity and the buffer capacity of the matrix are initially fixed at $10^{-12} \mathrm{~m}^{2} / \mathrm{s}$ and 0.15 , respectively. The length $(l)$ of the structural element is fixed at $5 \mathrm{~m}$, which is above the critical length for the assessment of the tangential stresses. This means that the results derived from the parametric study also apply to elements with bigger values of $l$. The additional input parameters required in the integrated model by [9] are fixed at the reference values adopted in section 3.1.3. 


\begin{tabular}{cccc}
\hline Parameter & Minimum & Reference & Maximum \\
\hline$C_{S O}[\mathrm{~g} / \mathrm{l}]$ & 0.6 & 3.0 & 4.2 \\
$C_{C A}\left[\% \mathrm{C}_{3} \mathrm{~A}\right]$ & 4 & 10 & 12 \\
\hline
\end{tabular}

553

554

555

556

557

558

559

560

561

562

563

564

565

566

567

568

569

570

571

572

573

574

575

576

577

578

579

580

581

582

583

The compressive strength and the elastic modulus of concrete are fixed at $30 \mathrm{MPa}$ and $28000 \mathrm{MPa}$, respectively. The elastic modulus was considered the same at the sound core and at the superficial layer affected by ESA. This consideration is on the safe side since it provides higher internal stresses in the equations from Table 5. The tensile strength $\left(f_{t}\right)$ of the material is approximated through the formulation included in the Model Code. The formulation proposed by Kaneko et al. [38] is used to estimate the shear strength, which gives a $\tau_{\max }$ of $7.1 \mathrm{MPa}$. This value is in agreement with experimental tests performed by Djazmati [39].

\section{1.- INFLUENCE OF $C_{S O}$}

Figure 8 shows the penetration depth at 25 and 50 years obtained with the integrated model by Ikumi et al. [9] and with the simplified equations (Eq. 2 and 3) for different sulfate concentrations. The curves corresponding to the simplified equations with the $95 \%$ probability $\left(K_{95}\right)$ are depicted in dotted lines. At both ages, the simplified equations derived in this study provide a good fit of the penetration front. The use of $K_{95}$ yields penetration depths above the expected values, ensuring conservative results.
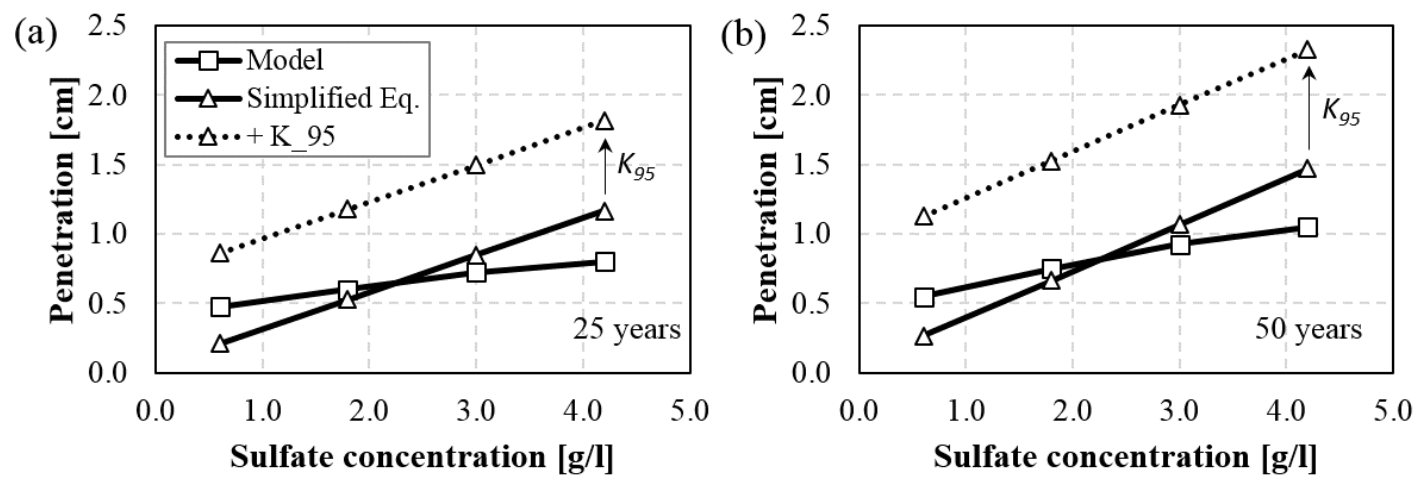

Fig. 8. Penetration depth for different sulfate concentrations

To evaluate the risk of mechanical failure, the maximum linear expansions $\left(\varepsilon_{\text {l.max }}\right)$ are calculated with Eq. 1, assuming that all aluminate react to form ettringite. This gives a $\varepsilon_{\text {l.max }}$ of $8.7 \cdot 10^{-4}$. Simplified equations presented in Table 5 for piles under full sulfate exposure are applied to calculate the tensile stress in the sound core $\left(\sigma_{t c}\right)$, the tangential stress $\left(\tau_{b}\right)$ and the tensile stress $\left(\sigma_{t b}\right)$ between the damaged and undamaged areas. Only penetration depths obtained through the simplified equation are evaluated. The ratio between each stress and the corresponding strength is calculated through Eq. 18 to 20 to make the risk of failure comparable for the different modes analyzed. The failure occurs if any of the ratios become bigger than 1 . 


$$
\begin{gathered}
\psi_{\text {Tensile core }}={ }^{\sigma_{t c}} / f_{t} \\
\psi_{\text {Tangential }}={ }^{\tau_{b}} / \tau_{\text {max }} \\
\psi_{\text {Tensile boundary }}={ }^{\sigma_{t b}} / f_{t}
\end{gathered}
$$

584

Figure 9 shows the stress/strength ratios at 25 and 50 years for piles with $90 \mathrm{~cm}, 40 \mathrm{~cm}$ and $30 \mathrm{~cm}$ of diameter under different sulfate exposure conditions. In these figures, the limit of failure is depicted with a discontinuous line.
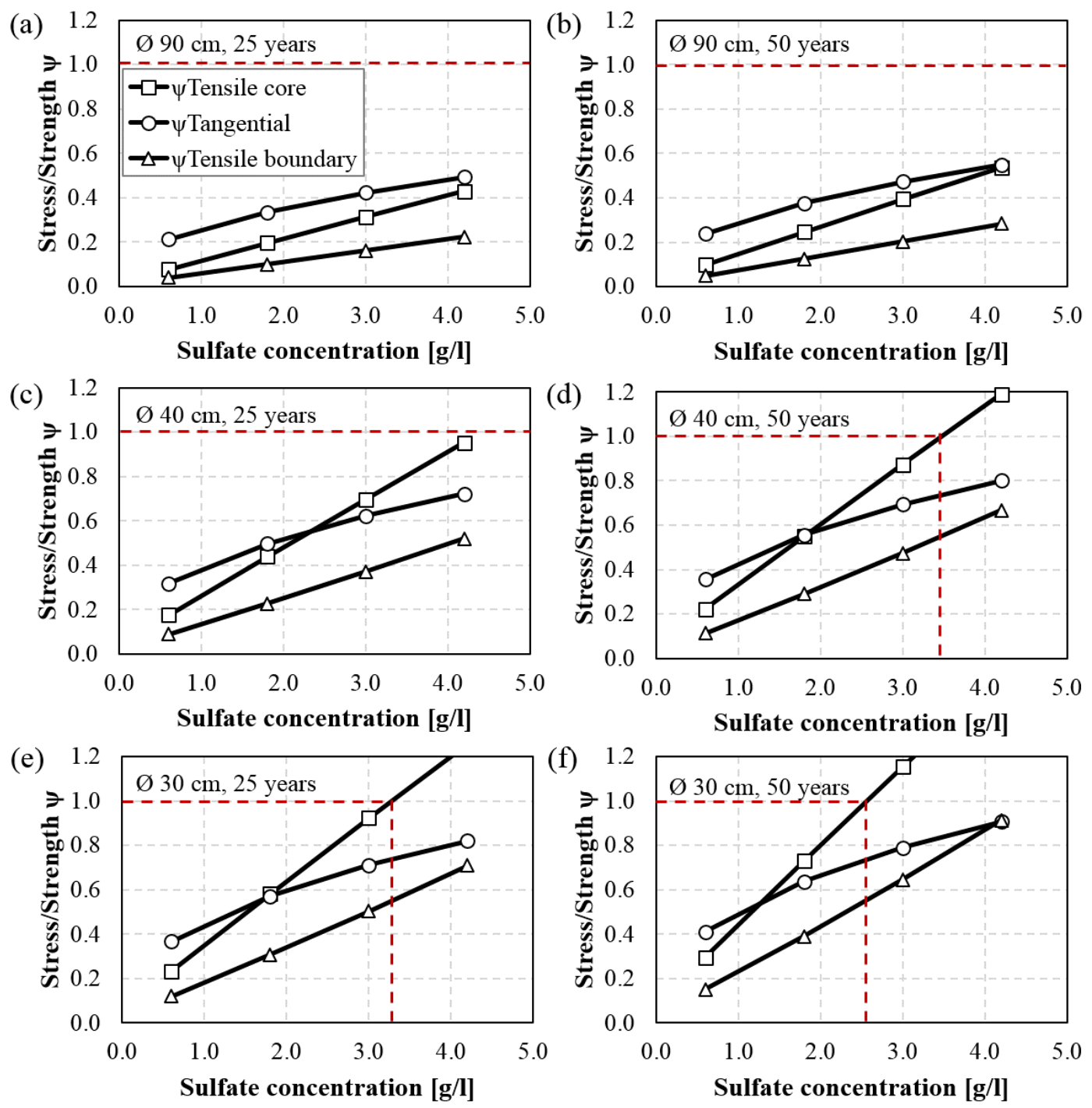

Fig. 9. Stress/strength ratio for different sulfate concentrations

Results for piles with $90 \mathrm{~cm}$ of diameter (Figures 9.a and 9.b) indicate no mechanical failure for any sulfate concentration below $4.2 \mathrm{~g} / \mathrm{l}$. The highest ratios are found for $\psi_{\text {Tangential }}$, followed by $\psi_{\text {Tensile core }}$ and $\psi_{\text {Tensile boundary. In piles with } 40 \mathrm{~cm} \text { of }}$ diameter, $\psi_{\text {Tangential }}$ are the highest for low sulfate exposure conditions, while $\psi_{\text {Tensile core }}$ become critical in severe sulfate exposure conditions. In fact, a tensile failure of the sound core may occur for sulfate concentrations above $3.4 \mathrm{~g} / \mathrm{l}$ at 50 years (Figure 9.d). Likewise, for piles with $30 \mathrm{~cm}$ of diameter, failure occurs according with 
the same mechanism for sulfate concentrations above $2.6 \mathrm{~g} / \mathrm{l}$ and $3.3 \mathrm{~g} / \mathrm{l}$ at 25 and 50 years, respectively (Figures 9.e and 9.f).

Results suggest that, for low sulfate concentrations, failure is likely to occur due to tangential stresses that causes surface delamination. Conversely, for higher sulfate concentrations, failure is likely to occur due to the tensile stresses at the sound core that causes cracking at the cross-section. This distinction is relevant since delamination of exterior layers may be accepted as long as it does not compromise the safety of the structure or the protection of the steel rebar. On the contrary, cracking of the crosssection should be taken with care especially in piles subjected to moments or to tensile forces.

Notice that according to the European standard UNE EN 206-1, the $10 \% \mathrm{C}_{3} \mathrm{~A}$ cement used in this parametric study is not allowed for sulfate concentrations above $0.6 \mathrm{~g} / \mathrm{l}$, regardless of the size of the pile. The estimations performed indicate that the limit established in the codes may be modified depending on the size of the element, the cement content and the mechanical properties of the concrete used in each application.

\section{2.- INFLUENCE OF $C_{3} A$ CONTENT}

Penetration depths predicted with the integrated model by Ikumi et al. [9] and with the simplified equations derived in this work are compared in Figure 10 for different $\mathrm{C}_{3} \mathrm{~A}$ contents at 25 and 50 years. Again, the simplified equations provide a good fit of the penetration depths at both ages. As described in section 4, the aluminate content has minor influence on the penetration front. However, it is one of the main parameters that define the magnitude of the maximum expansion in Eq. 1.
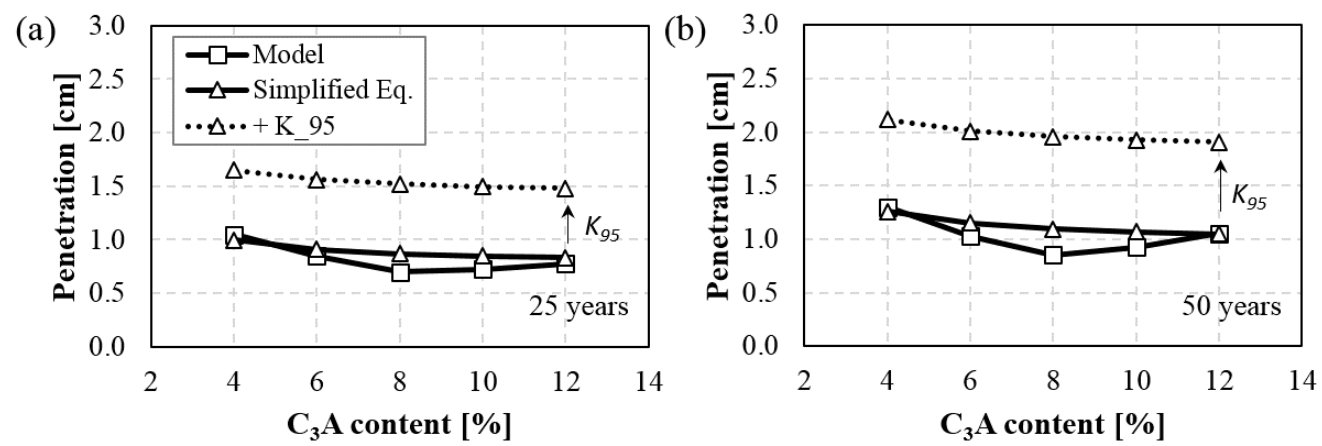

Fig. 10. Penetration depth for different aluminate contents

Figure 11 presents the stress/strength ratios for several $\mathrm{C}_{3} \mathrm{~A}$ contents in piles with 90 $\mathrm{cm}, 40 \mathrm{~cm}$ and $30 \mathrm{~cm}$ of diameter at 25 and 50 years. All curves present a similar trend, showing no failure for low contents of $\mathrm{C}_{3} \mathrm{~A}$. Once a threshold content is reached, all stress/strength ratios increase abruptly, indicating a high risk of failure. This trend is in agreement with the criteria included in structural codes, which establish a limiting $\mathrm{C}_{3} \mathrm{~A}$ content for sulfate resistant cements (usually 5\% to 6\%). Below this limit it is assumed that no unacceptable damage will take place. The fact that this criterion has been 
successfully applied in many structural elements worldwide suggests that the simplified formulation proposed here is capable of reproducing the general behavior of concrete structures subjected to sulfate attack.

Results in piles with $90 \mathrm{~cm}$ of diameter indicate failure due to tangential stresses for $\mathrm{C}_{3} \mathrm{~A}$ contents above $12 \%$. In piles with $40 \mathrm{~cm}$ and $30 \mathrm{~cm}$ of diameter, a tensile core failure is predicted for $\mathrm{C}_{3} \mathrm{~A}$ contents around $10 \%$. It is evident that the $\mathrm{C}_{3} \mathrm{~A}$ threshold depends on the size of the element, the cement content and the mechanical properties of the concrete.
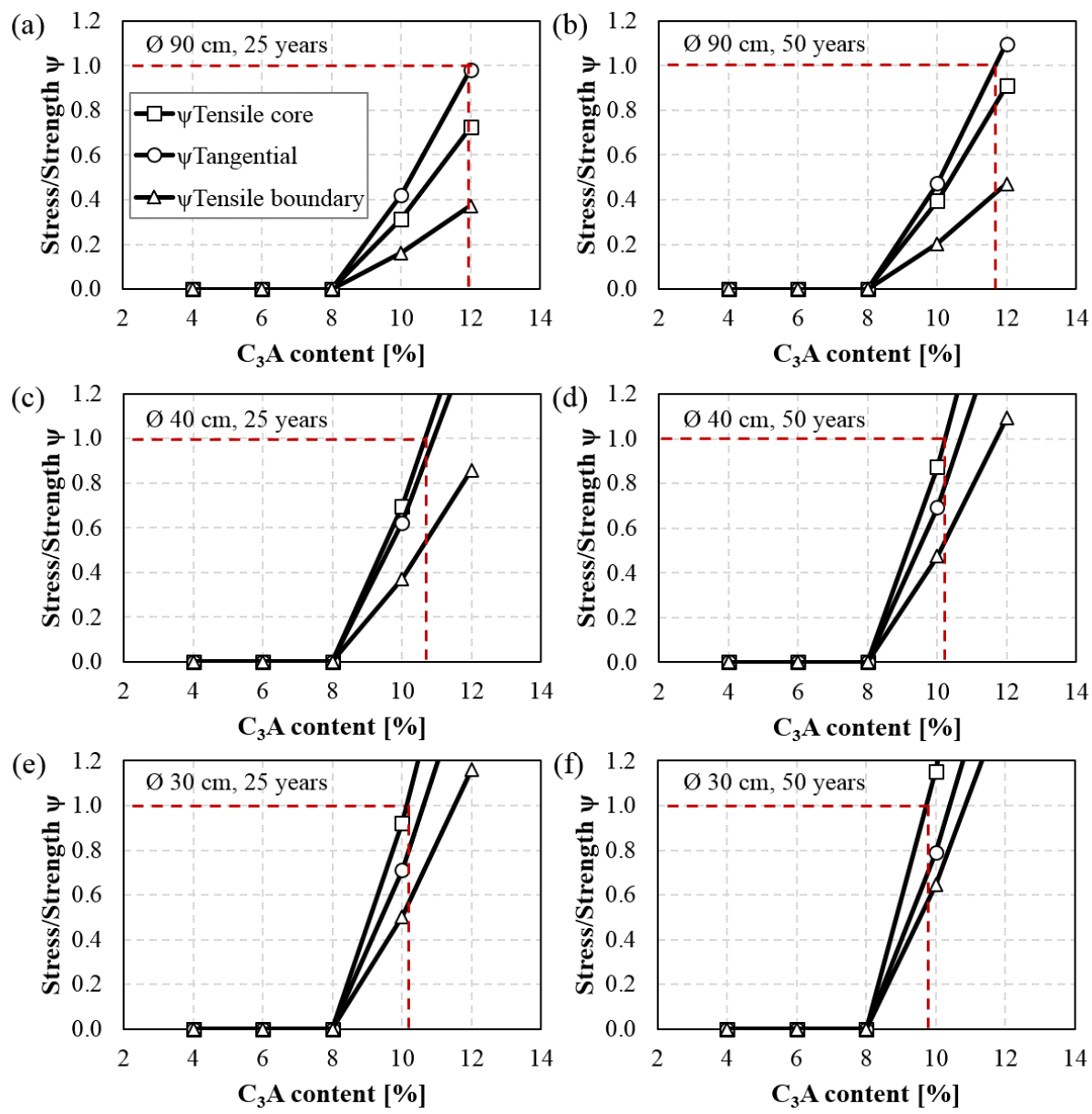

Fig. 11. Stress/strength ratio for different $C_{3} A$ contents

\section{3.- INFLUENCE OF BUFFER CAPCITY $(f)$}

Figure 12 shows the thresholds obtained for different pile diameters, buffer coefficients and sulfate exposure conditions at 25 and 50 years. Values above $12 \%$ and below $4 \%$ are not depicted since are beyond the range used to deduct the simplified formulation.

The results show that the increase in the diameter of the pile leads to an increase of the $\mathrm{C}_{3} \mathrm{~A}$ threshold. Nevertheless, the main parameter governing the $\mathrm{C}_{3} \mathrm{~A}$ threshold is the buffer coefficient $(f)$. According with Tixier and Mobasher [11], $f$ may vary between 0.05 and 0.40 . However, the results obtained suggest that values above 0.20 are not 
660

realistic, as the matrix is able to accommodate enough expansive products without any macro-structural damage for all exposure conditions considered. Therefore, a buffer capacity around 0.10 is proposed in the present study.
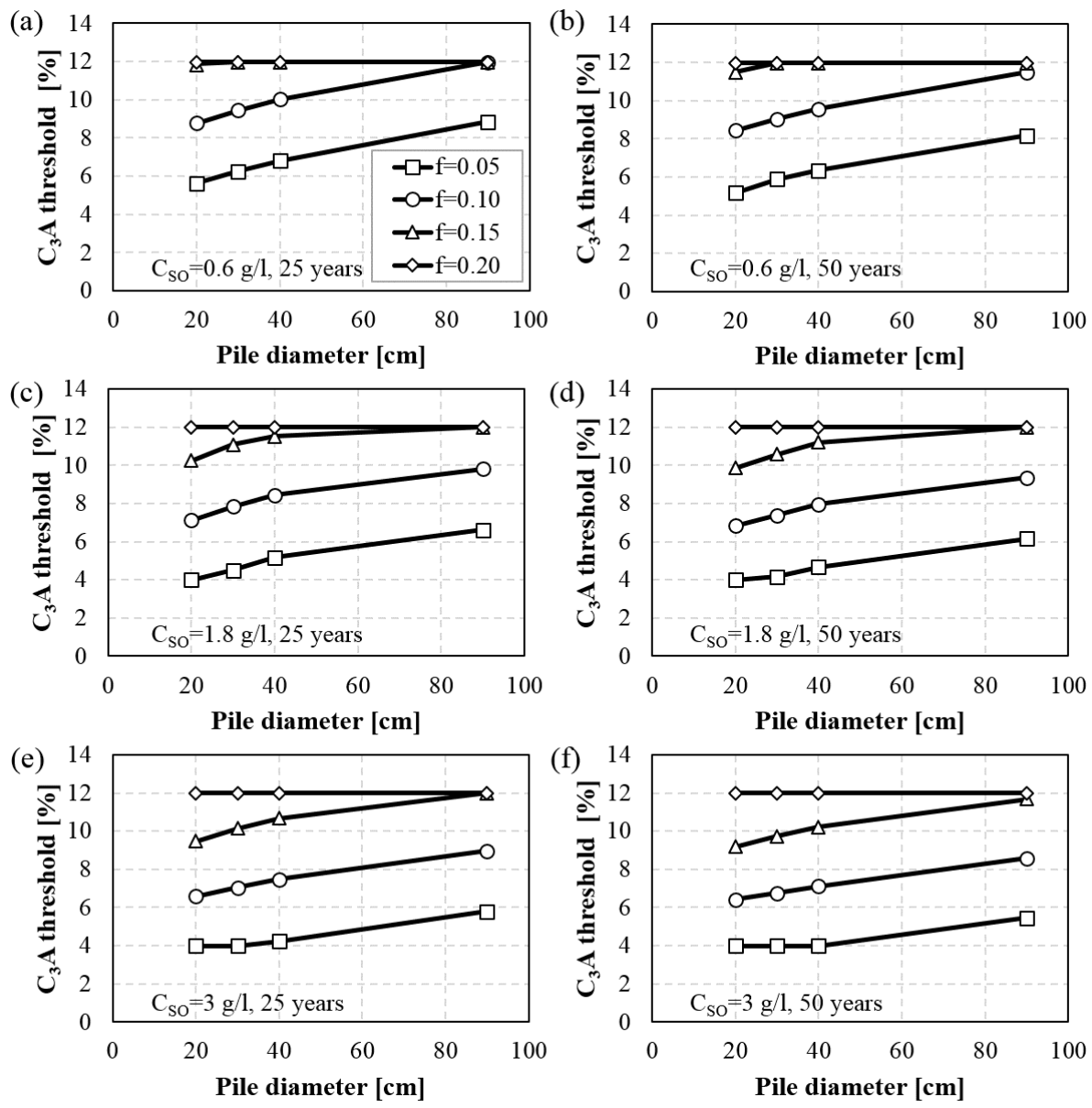

Fig. 12. $C_{3}$ A threshold for different pile diameters and buffer coefficients

\section{4.- PROPOSED $\mathrm{C}_{3} \mathrm{~A}$ THRESHOLD FOR PILES}

Reference $\mathrm{C}_{3} \mathrm{~A}$ threshold values calculated with the simplified model are presented for different exposure conditions and dimensions for service lives of 25 and 50 years. Table 7 corresponds to radial elements -piles-, whereas Table 8 and Table 9 correspond to elements such as walls under full or partial exposure, respectively.

Table 7. Proposed \% $C_{3}$ A threshold for a service life of 25 years and 50 years (in brackets).

\begin{tabular}{c|cccc}
\hline \multirow{2}{*}{$\boldsymbol{C}_{\text {So }}[\mathrm{g} / \mathrm{l}]$} & \multicolumn{4}{c}{ Pile diameter $[\mathrm{cm}]$} \\
\cline { 2 - 5 } & $\mathbf{2 0}$ & $\mathbf{3 0}$ & $\mathbf{4 0}$ & $\mathbf{9 0}$ \\
\hline $\mathbf{0 . 6}$ & $8.8(8.4)$ & $9.4(9.0)$ & $10.0(9.6)$ & $\geq 12.00(11.5)$ \\
\hline $\mathbf{1 . 8}$ & $7.1(6.8)$ & $7.8(7.4)$ & $8.4(8.0)$ & $9.8(9.4)$ \\
\hline $\mathbf{3 . 0}$ & $6.6(6.4)$ & $7.0(6.8)$ & $7.5(7.1)$ & $8.9(8.6)$ \\
\hline $\mathbf{4 . 2}$ & $6.3(6.2)$ & $6.7(6.5)$ & $7.0(6.7)$ & $8.5(8.0)$ \\
\hline
\end{tabular}


675

678

679

680

681

682

683

684

685

686

687

688

689

690

691

692

693

694

695

696

697

698

699

700

701

702

703

704

Table 8. Proposed \% $C_{3} A$ threshold for a service life of 25 years and 50 years (in brackets) in surface elements with.2 faces exposed.

\begin{tabular}{c|cccc}
\hline \multirow{2}{*}{$\boldsymbol{C}_{\text {So }}[\mathrm{g} / \mathbf{l}]$} & \multicolumn{4}{c}{ Surface element width [cm] } \\
\cline { 2 - 5 } & $\mathbf{2 0}$ & $\mathbf{3 0}$ & $\mathbf{4 0}$ & $\mathbf{9 0}$ \\
\hline $\mathbf{0 . 6}$ & $10.0(9.6)$ & $11.0(10.4)$ & $11.9(11.2)$ & $\geq 12.0(\geq 12.0)$ \\
\hline $\mathbf{1 . 8}$ & $8.5(7.9)$ & $9.1(8.7)$ & $9.6(9.2)$ & $11.5(10.9)$ \\
\hline $\mathbf{3 . 0}$ & $7.4(7.1)$ & $8.3(7.8)$ & $8.8(8.5)$ & $10.3(9.8)$ \\
\hline $\mathbf{4 . 2}$ & $7.0(6.7)$ & $7.6(7.2)$ & $8.2(7.7)$ & $9.6(9.2)$ \\
\hline
\end{tabular}

Table 9. Proposed \% $C_{3}$ A threshold for a service life of 25 years and 50 years (in brackets) in surface elements with.1 face exposed.

\begin{tabular}{c|cccc}
\hline \multirow{2}{*}{$\boldsymbol{C}_{\text {So }}[\mathrm{g} / \mathrm{l}]$} & \multicolumn{4}{c}{ Surface element width $[\mathrm{cm}]$} \\
\cline { 2 - 5 } & $\mathbf{2 0}$ & $\mathbf{3 0}$ & $\mathbf{4 0}$ & $\mathbf{9 0}$ \\
\hline $\mathbf{0 . 6}$ & $9.4(8.6)$ & $11.0(10.1)$ & $11.9(11.2)$ & $\geq 12.0(\geq 12.0)$ \\
\hline $\mathbf{1 . 8}$ & $7.2(6.9)$ & $7.9(7.5)$ & $8.6(8.0)$ & $11.5(10.9)$ \\
\hline $\mathbf{3 . 0}$ & $6.7(6.5)$ & $7.1(6.8)$ & $7.5(7.2)$ & $9.8(9.0)$ \\
\hline $\mathbf{4 . 2}$ & $6.4(6.3)$ & $6.7(6.5)$ & $7.1(6.8)$ & $8.7(8.1)$ \\
\hline
\end{tabular}

The values recommended in Tables 7 to 9 are applicable to concretes with $350 \mathrm{~kg}$ of cement per cubic meter, an $f$ equal to 0.10 , the sulfate diffusivity and concrete mechanical properties considered in the parametric study. Once more the values confirm that the $\mathrm{C}_{3} \mathrm{~A}$ threshold depends on the dimensions of the element and the exposure conditions. It is also observed that for equivalent conditions the threshold for piles tends be smaller than that obtained for walls or tunnels. This is the result of the bigger ratio between exposed surface and the total volume found in piles.

In case a different cement content is used, the values from all tables should be multiplied by 350 and divided by the actual content in $\mathrm{kg}$ per cubic meter of concrete. Moreover, in case an $f$ equal to 0.05 should be considered, the values from Tables 7, 8 and 9 should be multiplied by $0.63,0.66$ and 0.60 , respectively.

\section{5.- CONCLUSIONS}

A simplified methodology that considers the transport-reaction and the damage at a macro-structural level due to the ESA was proposed. This methodology allows a direct and simple assessment of the risk of failure for elements (piles, walls and tunnels) exposed to a sulfate rich environment, considering the conditions found in each application. The following conclusions may be derived from this study.

- Flux intensification effect of the sulfate ions in radial elements plays a minor role in the maximum penetration depth for the typical size of real structures. Therefore, unidirectional flux is adopted for all structural typologies, thus avoiding the use of different formulations and the consideration of the element size in the simplified reactive-transport equations. 
- Sulfate and aluminate concentration, initial diffusivity and the buffer coefficient are the most influencing parameters for the estimation of the penetration front. Changes in the compressive strength and initial porosity display a smaller influence on the penetration depth.

- According to the results obtained, buffer capacities above 0.20 of the initial porosity are not realistic. Therefore, buffer capacities between 0.05 and 0.20 should be used.

- For lower sulfate concentrations and bigger pile diameters, failure is likely to occur due to tangential stresses that causes surface delamination. On the other hand, for bigger sulfate concentrations and lower pile diameters, failure is likely to occur due to the tensile stresses at the sound core that causes cracking at the cross-section.

- The simplified methodology suggests the existence of a $\mathrm{C}_{3} \mathrm{~A}$ threshold above which a high risk of structural damage occurs. This trend is consistent with the philosophy used in structural codes and validated in practice. The $\mathrm{C}_{3} \mathrm{~A}$ threshold increases with the increase of the size of the element and with the reduction of the sulfate concentration.

- Reference values are proposed for the $\mathrm{C}_{3} \mathrm{~A}$ threshold depending on the exposure conditions, type and dimensions of the structure. In case a more precise assessment is required, the equation included in the simplified methodology may be used to estimate the $\mathrm{C}_{3} \mathrm{~A}$ threshold. The procedure followed for this estimation requires the use of the formulation included in Tables 4 and 5, being compatible with the durability assessment found in building codes.

\section{ACKNOWLEDGMENTS}

Support from the Spanish Ministry of Economy and Competitiveness through research project BIA2013-49106-C2-1-R is greatly acknowledged. T. Ikumi is supported by the fellowship program FPI of the Spanish Ministry of Economy and Competitiveness.

\section{REFERENCES.}

[1] C. Ayora, S. Chinchón, A. Aguado, F. Guirado, Weathering of iron sulfides and concrete alteration: Thermodynamic model and observation in dams from central Pyrenees, Spain, Cem. Concr. Res. 28 (1998) 591-603.

[2] J.P. Skalny, I. Odler, J. Marchand, Sulfate Attack on Concrete, Spon, London, (2001).

[3] A. Neville, The confused world of sulfate attack on concrete, Cem. Concr. Res. 34 (2004) 1275-1296.

[4] J.S. Chinchón, C. Ayora, A. Aguado, F. Guirado, Influence of weathering of iron sulfides contained in aggregates on concrete durability. Cem. Concr. Res. 25 (1995) 1264-1272. 

the deterioration of mortars and pastes exposed to sulfate solutions at ambient temperature, Cem. Concr. Res. 38 (2008) 68-76.

750 [6] A. Atkinson, J.A. Hearne, An assessment of the long-term durability of concrete in radioactive waste repositories, MRS Proceedings 50 (1985) 239.

752 [7] A. Atkinson, J.A. Hearne, Mechanistic model for the durability of concrete

753 barriers exposed to sulphate-bearing groundwaters, Mat. Res. Soc. Symp. Proc. 176 754 (1990) 149-156.

755 [8] K. E. Kurtis, P. J. Monteiro, Empirical models to predict concrete expansion caused by sulfate attack, ACI Materials J. 97 (2000) 156-161 (errata publ. 97:713).

757 [9] T. Ikumi, S.H.P. Cavalaro, I. Segura, A. Aguado, Alternative methodology to consider damage and expansions in external sulfate attack modeling, Cem. Concr. Res. 63 (2014) 105-116.

760 [10] C. Yu, K. Scrivener, Mechanism of expansion of mortars immersed in sodium sulphate solution, Cem. Concr. Res. 43 (2013) 105-111. [11] R. Tixier, B. Mobasher, Modeling of Damage in Cement-Based Materials Subjected to External Sulfate Attack. I: Formulation, J. Mater. Civ. Eng. 15 (2003) 305313.

[12] R. Tixier, B. Mobasher, Modeling of damage in cementbased materials subjected to external sulfate attack. II: Comparison with experiments, J. Mater. Civ. Eng. 15 (2003) 314-322.

[13] B. Bary, Simplified coupled chemo-mechanical modeling of cement pastes behavior subjected to combined leaching and external sulfate attack, Int. J. Numer. Anal. Meth. Geomech. 32 (2008) 1791-1816. [14] S. Sarkar, S. Mahadevan, J.C.L. Meeussen, H. van der Sloot, D.S. Kosson, Numerical simulation of cementitious materials degradation under external sulfate attack, Cem. Concr. Compos. 32 (2010) 241-252. [15] A.E. Idiart, C.M. López, I. Carol, Chemo-mechanical analysis of concrete cracking and degradation due to external sulfate attack: A meso-scale model,» Cem.

777 [16] X.B. Zuo, W. Sun, C. Yu, Numerical investigation on expansive volume strain in concrete subjected to sulfate attack, Constr. Build. Mater. 36 (2012) 404-410.

779 [17] N. Cefis, C. Comis, Damage modelling in concrete subject to sulfate attack, 780 Frattura ed Integrità Strutturale vol.:8 núm:29 (2014) 222-229.

781 [18] B. Bary, N. Leterrier, E. Deville, P.L. Bescop, Coupled chemo-transport782 mechanical modelling and numerical simulation of external sulfate attack in mortar, 783 Cem. Concr. Comp. 49 (2014) 70-83.

784 [19] Q. Nie, C. Zhou, H. Li, X. Shu, H. Gong, B. Huang, Numerical simulation of fly 785 ash concrete under sulfate attack, Constr. Build. Mater. 84 (2015) 261-268.

786 [20] W. Müllauer, R.E. Beddoe, D. Heinz, Sulfate attack expansion mechanisms, 787 Cem. Concr. Res. 52 (2013) 208-215.

788 [21] J.R. Clifton, J.M. Pommersheim, Sulfate attack of cementitious materials: 789 volumetric relations and expansions, NISTIR 5390, Building and Fire Research 790 Laboratory, Gaithersburg (MD), 1994. 

1613-1624.

[23] R.J. Flatt, G.W. Scherer, Thermodynamics of crystallization stresses in DEF, Cem. Concr. Res. 38 (2008) 325-336.

[24] C.W. Correns, Growth and dissolution of crystals under linear pressure, Discuss Faraday Soc 5 (1949) 267-271.

[25] M. Steiger, Crystal growth in porous materials I: the crystallization pressure of large crystals, J. Cryst. Growth. 282 (2005) 455-469.

[26] W. Kunther, B. Lothenbach, K. Scrivener, Influence of bicarbonate ions on the deterioration of mortar bars under sulfate attack, Cem. Concr. Res. 44 (2013) 77-86. [27] W. Kunther, B. Lothenbach, K. Scrivener, On the relevance of volume increase for the length changes of mortar bars in sulfate solutions, Cem. Concr. Res. 46 (2013) 23-29.

[28] M. Zhang, J. Chen, Y. lv, D. Wang, J. Ye, Study on the expansion of concrete under attack of sulfate and sulfate-chloride ions, Const. \& Build. Mat. 39 (2013),26-32. [29] B. Gérard, J. Marchand, Influence of cracking on the diffusion properties of cement-based materials. Part I: Influence of continuous cracks on the steady-state regime, Cem. Concr. Res. 30 (2000) 37-43.

[30] D.A. Hordijk, Local Approach to Fatigue of Concrete, Phd Thesis, Delft University of Technology, Delft, 1991.

[31] I. Oliveira, S.H.P. Cavalaro, A. Aguado, New kinetic model to quantify the internal sulfate attack in concrete, Cem. Concr. Res. 43 (2013) 95-104.

[32] R. Tixier, Microstructural development and sulphate attack modeling in blended cement-based materials, PhD Thesis, Arizona State University, Tempe, 2000.

[33] P.W. Brown, An evaluation of the sulfate resistance of cements in a controlled environment, Cem. Concr. Res. 11 (1981) 719-727.

[34] A. Chabrelie, Mechanisms of Degradation of Concrete by External Sulfate Ions under Laboratory and Field Conditions, PhD Thesis, ÉPFL, Lausanne, 2010.

[35] A. Kelly, Strong solids, Clarendon 1966.

[36] A. Jayatilaka, Fracture of engineering brittle materials, Applied Science Publishers, 1979.

[37] S. Oller, Simulación numérica del comportamiento mecánico de los materiales compuestos, CIMNE 74 (2003).

[38] Y. Kaneko, H. Mihashi and S. Ishihara, Shear failure of plain concrete in strain localized area, Proceeding of the Fifth International Conference on Fracture Mechanics of Concrete and Concrete Structures, Colorado, USA, V.C. Li, C.K.Y. Leung, K.J. Willam and S.L. Billington (ed.), 12-16 Vol.1 (2004) 383-390.

[39] B. Djazmati and J.A. Pincheira, Shear stiffness and strength of horizontal construction joints, ACI Structural J. 101 (2004) 484-493. 